\title{
PROBABILISTIC ANALYSIS OF THE FRAGILITY OF REACTOR BUILDINGS ON THE IMPACT OF EXTREME CLIMATIC LOADS
}

\author{
J. Králik* , J. Králik, jr.**
}

\begin{abstract}
This paper gives the results of the probabilistic analysis of the nuclear power plants safety in Slovakia. The probabilistic assessment of NPP structures for Probabilistic Safety Analysis (PSA) level 2 of VVER 440/213 in the case of the extreme external even without the earthquake is presented. On the base of the meteorological monitoring of the locality the extreme load parameters were defined for the return period $10^{4}$ years using the Monte Carlo simulations. There is showed summary of calculation models and calculation methods for the probability analysis of the structural resistance. The numerical simulations on the base of the LHS method were realized in the system ANSYS and FReET.
\end{abstract}

Keywords: Nuclear power plants, Extreme climatic loads, Probability, ANSYS, FReET.

\section{Introduction}

This paper deals with the resistance of the steel hale frame of the nuclear power plant (NPP) in locality J. Bohunice. The international organization IAEA in Vienna (IAEA, 2003, 2011) set up the design requirements for the safety and reliability of the NPP structures. The extreme environmental events (e.g. wind, temperature, snow, explosion...) (IAEA, 2011, Králik, 2009, 2015, 2017 Steward, 2016 and NRA SR, 2011, NRC RG1.200, 2009) are the important loads from the point of the NPP safety performance. The extreme wind loads are defined with the probability of mean return period equal to one per $10^{4}$ years.

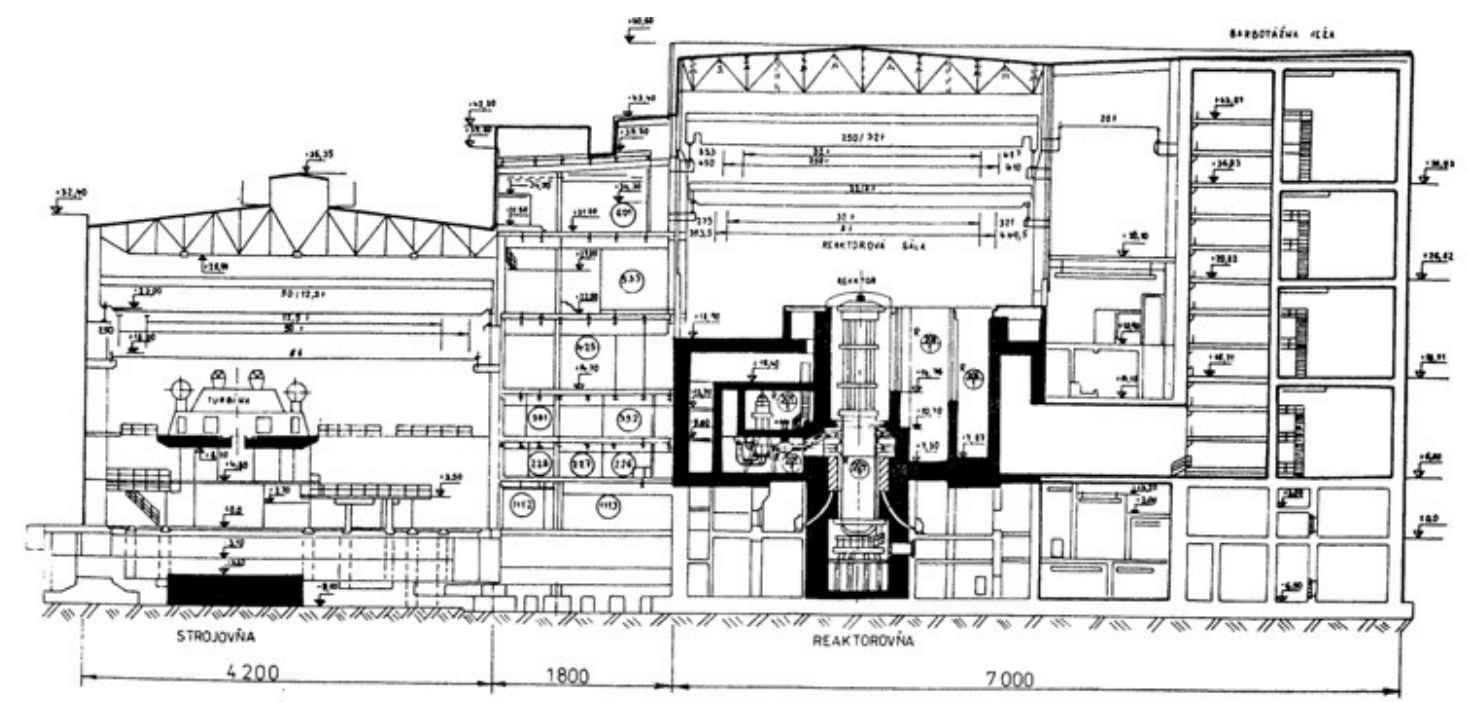

Fig. 1: Section plane of the NPP with reactor WWER440.

\footnotetext{
Prof. Ing. Juraj Králik, CS.: Slovak University of Technology in Bratislava, Faculty of Civil Engineering, Radlinskeho 11, 810 05, Bratislava, Slovakia, juraj.kralik@stuba.sk.

** Ing. Juraj Králik, PhD.: Academy of Fine Arts and Design in Bratislava, Hviezdoslavovo nam. 18, 814 37, Bratislava, Slovakia, ing.kralikj@hotmail.com.
} 
The NRC (NRC RG 1.200, 2009) uses Probabilistic Risk Assessment (PRA) to estimate risk by computing real numbers to determine what can go wrong, how likely is it, and what are its consequences. Thus, PRA provides insights into the strengths and weaknesses of the design and operation of a nuclear power plant.

For the type of nuclear plant a PRA can estimate three levels of risk :

- A Level 1 PRA estimates the frequency of accidents that cause damage to the nuclear reactor core. This is commonly called core damage frequency (CDF).

- A Level 2 PRA, which starts with the Level 1 core damage accidents, estimates the frequency of accidents that release radioactivity from the nuclear power plant.

- A Level 3 PRA, which starts with the Level 2 radioactivity release accidents, estimates the consequences in terms of injury to the public and damage to the environment.

The definition of the fragility curve of a nuclear power plant structures (NPP) generally represents a crucial step for the level 2 probabilistic safety assessment (PSA L2), where the probability of structure failure can be evaluated as the convolution of the fragility curve with the load curve. The assessment of the structural strength of the nuclear power plant has acquired even a greater importance in the framework of postFukushima stress tests where the assessment of the safety margin and off-design conditions (NRA SR, 2011).
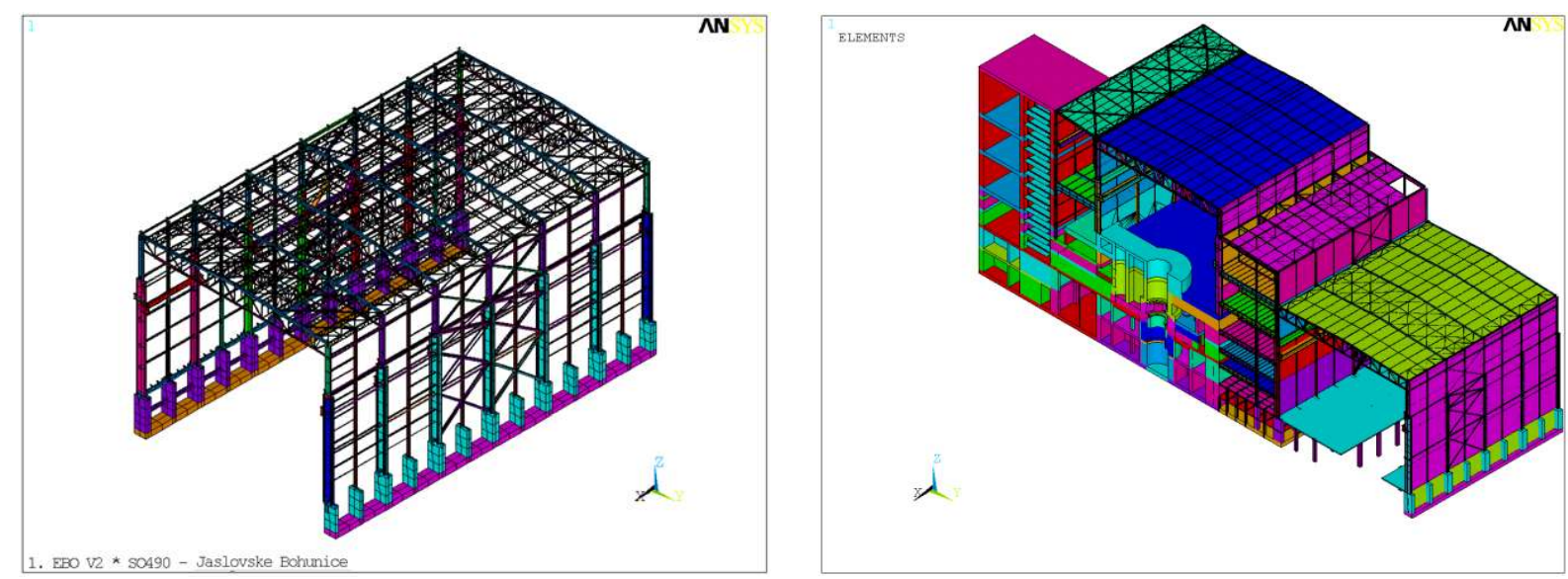

Fig. 2: Calculation Model of the Hall Frame (left), Scheme of the NPP building half (right).

The NPP buildings with the reactor VVER 440/213 consists the turbine hall, middle building, reactor building and bubble condenser (Figure 1). The building of the power block was idealized with a FEM model consisting of 159037 elements with 444454 DOF (Figure 2) in program ANSYS (Králik, 2009).

\section{Probabilistic Assessment}

A great attention should be paid to using the probabilistic approach in an analysis of the reliability of structures (Antuchevivience, 2015, Diamantidis, 2016, Haldar, 2000, JCSS, 2011, Kala 2011, Králik, 2009, 2015, 2017, Konečný, 2009, Krejsa, 2016, Melcher 1999, Novák, 2003, Sýkora, 2013). Most problems concerning the reliability of building structures are defined today as a comparison of two stochastic values, loading effects $E$ and the resistance $R$, depending on the variable material and geometric characteristics of the structural element. The probabilistic definition of the reliability condition is of the form

$$
R F=g(R, E)=R-E \geq 0
$$

where $g(R, E)$ is the reliability function. In the case of simulation methods the failure probability is defined as the best estimation on the base of numerical simulations in the form

$$
p_{f}=\frac{1}{N} \sum_{i=1}^{N} I\left[g\left(X_{i}\right) \leq 0\right]
$$

where $N$ in the number of simulations, $g($.$) is the failure function, I[$.$] is the function with value 1$, if the condition in the square bracket is fulfilled, otherwise is equal 0. 


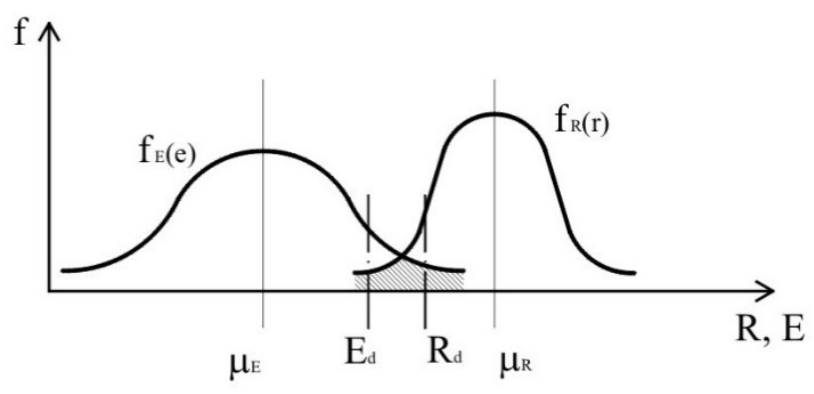

Fig. 3: Traditional reliability conditions.

\section{Action effects to NPP structures}

The IAEA requirement (IAEA, 2011) proposes to calculus the structure for situations - test conditions, design accident conditions, service conditions and the extreme environmental conditions. The load combination of the deterministic and probabilistic calculation is considered according to ENV 1990 (Diamantidis, 2016) and IAEA for the ultimate limit state of the structure as follows:

- Deterministic method-extreme design situation

$$
E_{d}=\gamma_{g} G_{k}+\gamma_{q} Q_{k}+\gamma_{a} A_{k}
$$

- Probabilistic method - extreme design situation

$$
E=G+Q+A_{E}=g_{\mathrm{var}} G_{k}+q_{\mathrm{var}} Q_{k}+a_{\mathrm{var}} A_{E . k}
$$

where $G_{k}$ is the characteristic value of the permanent dead loads, $Q_{k}$ - the characteristic value of the permanent live loads, $A_{k}$ - the characteristic value of the extreme loads, $\gamma_{g}, \gamma_{q}, \gamma_{a}$ are the loading parameters $\left(\gamma_{g}=\gamma_{q}=\gamma_{a}=1\right.$ for the extrem design situation), $g_{v a r}, q_{v a r}, a_{v a r}$ are the variable parameters defined in the form of the histogram calibrated to the load combination in compliance with Eurocode and JCSS requirements (Haldar, 2000, JCSS, 2001, Diamantidis, 2016, Melchers, 1999).

\section{Reliability margin of steel structures}

Reliability margin of steel structures was checked in accordance of national standards, Eurocodes and requirements of US NEA (NRC RG 1.200, 2009) on the ultimate limit state for median values of the effect of action and resistance. The failure function (1) for the linearized interaction diagram may be defined in the form (Králik, 2009)

$$
g(N, M)=1-\left(N_{o}+\eta_{u} N_{E x}\right) / N_{R}-\left(M_{o}+\eta_{u} M_{E x}\right) / M_{R}=0
$$

where $N_{R u}$ and $M_{R u}$ are the values of limit normal force and moment on the axis of interaction diagram $N_{R u}=N_{R}(M=0)$ and $M_{R u}=M_{R}(N=0)$.

The total internal forces of the action effect are defined as follow

$$
M_{E}=M_{o}+M_{E x} \text { and } N_{E}=N_{o}+N_{E x}
$$

where $N_{o}, M_{o}$ are initial values of normal forces and moments due to performance load and $N_{E x}, M_{E x}$ are normal forces and moments of the extreme load.

The moment of resistance $M_{R}$ on the interaction diagram can be calculated from known normal force $N$ in the form

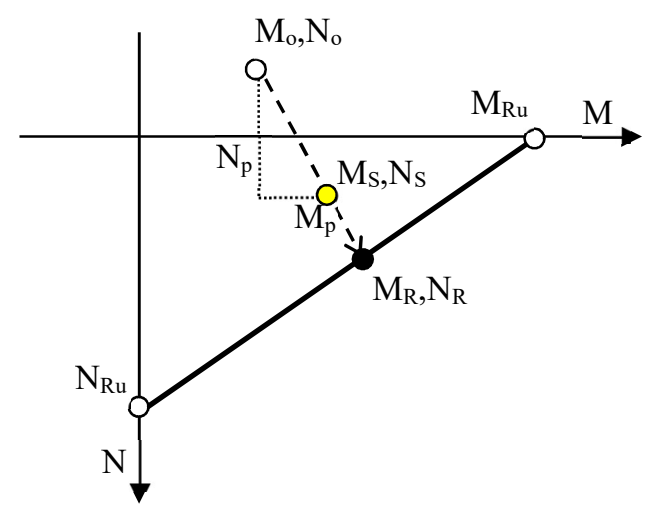

Fig.4: Linearization of interaction diagram.

$$
M_{R}=M_{R u}-\left(M_{R u} / N_{R u}\right) N
$$

The moment of action effect $M_{E}$ can be expressed for an initial values $M_{o}, N_{o}$ and an increment of pressure $M_{E x}, N_{E x}$ in the form 


$$
M_{E}=M_{o}-\left(M_{E x} / N_{E x}\right)\left(N-N_{o}\right),
$$

The failure condition will be fulfilled if we have

$$
M_{E}=M_{R}
$$

If the relation (7) and (8) give (9) we have the value of normal force $N$ on the interaction diagram $\left(N=N_{R}\right)$

$$
N_{R}=\frac{M_{R u}-M_{o}+\left(M_{E x} / N_{E x}\right) N_{o}}{\left(M_{R u} / N_{R u}\right)+\left(M_{E x} / N_{E x}\right)}
$$

The reliability margin $\eta$ can be expressed from (5) as follows

$$
\eta=\left(N_{R}-N_{o}\right) / N_{E x}=\left(\frac{M_{R u}-M_{o}+\left(M_{E x} / N_{E x}\right) N_{o}}{\left(M_{R u} / N_{R u}\right)+\left(M_{E x} / N_{E x}\right)}-N_{o}\right) / N_{E x}
$$

where $N_{\mathrm{o}}, M_{\mathrm{o}}$ (resp. $N_{\mathrm{Ex}}, M_{\mathrm{Ex}}$ ) are the initial (resp. extreme) values of the normal forces and moments, $N_{\mathrm{R}}$ is the normal force on the interaction diagram and $N_{\mathrm{Ru}}$ and $M_{\mathrm{Ru}}$ are the values of limit normal force and moment on the axis of interaction diagram. The failure action of extreme load $p_{u}$ can be expressed from the interaction diagram as follows

$$
p_{u}=\eta \cdot p_{E x}=p_{E x} \cdot\left(N_{R}-N_{o}\right) / N_{E x}
$$

\section{Extreme snow load}

The load on a structure due to the snowpack will depend on both snow depth and packing density. The extreme snow load for the locality J. Bohunice was defined on the base of the last result of the SHMU investigations (SHMU, 2012) in accordance of the Eurocode requirements.

The characteristic value of the extreme snow load according to STN ENV 1991 is defined following

$$
s_{k}=a+A / b=0,454+\frac{176}{970}=0,635 \mathrm{kNm}^{-2}
$$

where $a, b$ are the factors depended on the map zone, $A$ is the altitude of the NPP area.

The characteristic value of the snow load at roof is

$$
s_{k}=\mu_{i} \cdot C_{e} \cdot C_{t} \cdot s_{A d}=1,064 k P a,
$$

where $\mu_{\mathrm{i}}$ is the snow load shape coefficient, $C_{\mathrm{e}}$ is the exposure coefficient, $C_{\mathrm{t}}$ is the thermal coefficient.

The extreme snow load is defined for the probability of $10^{-4}$ by year on the base of the IAEA requirements (IAEA, 2011) twice the characteristic snow load value:

$$
s_{A d}=C_{e s l} . s_{k}=2,1.0,635=1,33 \mathrm{kNm}^{-2}
$$

The Gumbel probability distribution is recommended for the extrapolation the measured data.

\section{Extreme wind load}

The load on a structure due to the wind will depend on both wind velocity and terrain roughness. The wind velocity and the velocity pressure are composed of a mean and a fluctuating component. The mean wind velocity $v_{m}$ should be determined from the basic wind velocity $v_{b}$ which depends on the wind climate and the height variation of the wind determined from the terrain roughness and orography. The fluctuating component of the wind is represented by the turbulence intensity. The extreme wind load is defined for the probability of $10^{-4}$ by year on the base of the IAEA requirements (IAEA, 2011) twice the characteristic wind load value:

$$
v_{A d}=2 v_{b}=48 \mathrm{~m} / \mathrm{s} \text { and therefore } q_{A d}=(1 / 2) \cdot \rho \cdot v_{A d}^{2}=(1 / 2) \cdot 0,00125 \cdot 48^{2}=1,44 \mathrm{kN} / \mathrm{m}^{2}
$$




\section{Uncertainties of input data}

The uncertainties of the input data - action effect and resistance are for the case of the probabilistic calculation of the structure reliability defined in JCSS (JCSS, 2011) and Eurocode 1990 (Diamantidis, 2016). The input data are defined by the characteristic values and the variable coefficient (Table 1).

Tab. 1: The histograms of the input data

\begin{tabular}{lccccc}
\hline & \multicolumn{2}{c}{ Quantities } & \multicolumn{3}{c}{ Histograms } \\
\hline Input data & Character. value & Variable value & Type & Mean $\mu$ & Deviation $\sigma[\%]$ \\
\hline Dead load & $G_{\mathrm{k}}$ & $g_{\text {var }}$ & Normal & 1.0 & 1 \\
Live load & $Q_{k}$ & $q_{\text {var }}$ & Gumbel & 0.6 & 25 \\
Snow & $P_{\mathrm{k}}$ & $p_{\text {var }}$ & Gumbel & 0.6 & 20 \\
Wind & $W_{\mathrm{k}}$ & $w_{\text {var }}$ & Gumbel & 0.6 & 20 \\
Strength & $F_{\mathrm{k}}$ & $f_{\text {var }}$ & Lognormal & 1.0 & 1 \\
Model & $E_{\mathrm{k}}$ & $e_{\text {var }}$ & Normal & 1.0 & 5 \\
Resistance & $R_{\mathrm{k}}$ & $r_{\mathrm{var}}$ & Normal & 1.0 & 5 \\
\hline
\end{tabular}

\section{Fragility curve of frame}

The probability of the frame failure was determined by the probabilistic linear analysis by the simulation in LHS method using program FReET (Novák, 2003). The fragility curve was calculated for various levels of snow and wind loads using the results from the linear analysis of the steel hall frame.
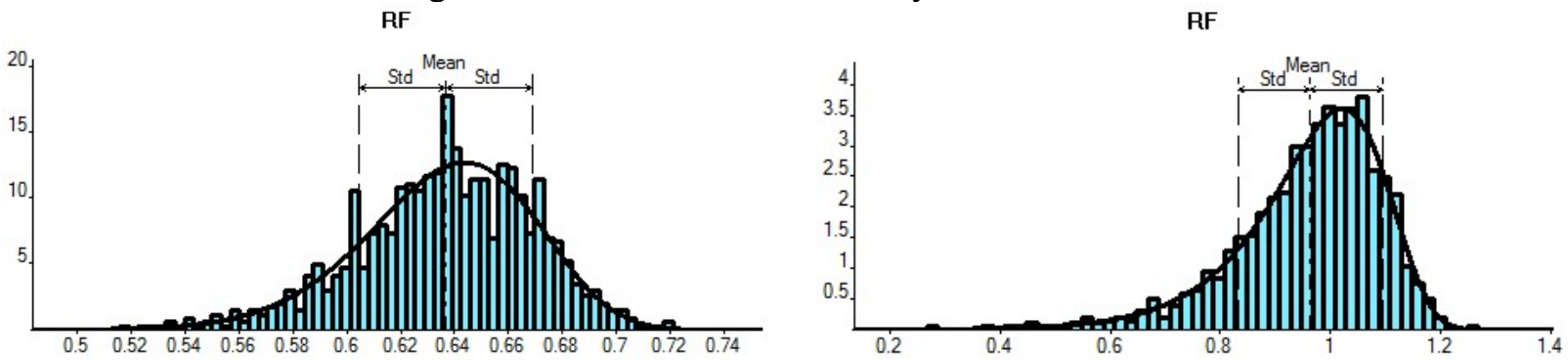

Fig.5: Histogram of the failure function RF for the extreme snow and wind load.

The results from the numerical linear analysis and the idealized fragility curves of the steel hall frame are presented in Fig.ures 5 and 6 . The $5 \%$ probability of the steel frame collaps results under snow loads equal to $p_{S .0,05}=13,85 p_{S . E x}$ or under wind loads $p_{W, 0.05}=3,04 p_{W . E x}$. The $95 \%$ probability of the steel frame collaps results under snow loads equal to $p_{S .0,95}=37,74 p_{S . E x}$ or under wind loads $p_{W .0,95}=8,92 p_{W . E x}$.
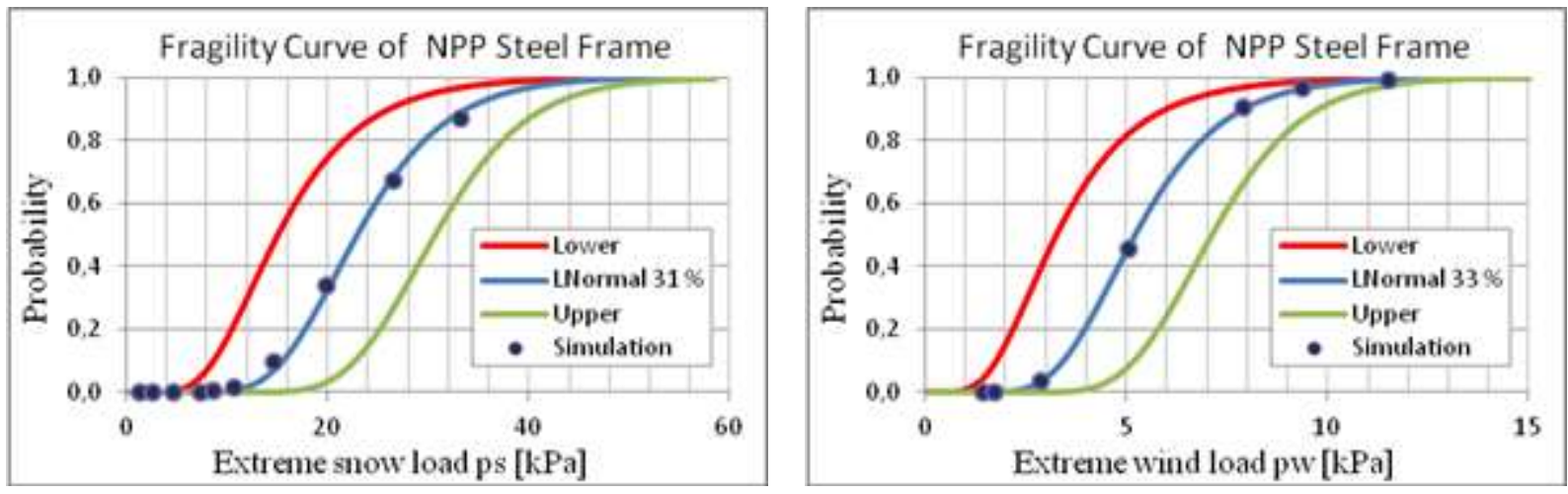

Fig.6: Idealized fragility curves of the steel hall frame for extreme snow and wind load with the lower and upper boundary equal to standard deviation $\pm \sigma$.

\section{Conclusion}

This paper gives the results of the risk-based safety analysis of the nuclear power plants in Slovakia (Králik, 200+9, 2017). The probabilistic assessment of NPP structures for Probabilistic Safety Analysis (PSA) level 
2 of VVER 440/213 in the case of the extreme external even without the earthquake was presented. On the base of the meteorological monitoring of the locality the extreme load parameters were defined for the return period $10^{4}$ years using the Monte Carlo simulations. There was showed summary of calculation models and calculation methods for the probability analysis of the structural resistance. The reliability analysis of the steel hall frame resistance due to extreme snow and wind loads (Králik, 2009) were presented in this paper. The $5 \%$ probability of the steel frame collaps results under snow loads equal to $p_{S .0,05}=13,85 p_{S . E x}$ or under wind loads $p_{W, 0.05}=3,04 p_{W . E x}$. The probability of failure was calculated on program FReET using LHS method (Novák, 2003). The probability of steel frame failure under extreme snow and wind load is lower than $10^{-6}$. This paper presented the methodology and application of the probabilistic analysis of the safety and reliability of the NPP structures under the extreme climatic loads.

\section{Acknowledgements}

This article was created with the support of the Ministry of Education of Grant Agency of the Slovak Republic (grant VEGA No. 1/0265/16).

\section{References}

Antucheviciene, J. et al. (2015) Decision Making Methods and Applications in Civil Engineering, Mathematical Problems in Engineering, Art. Num. 160569, p.3, ISSN: 1024-123X.

Diamantidis, D. et al. (2016) Risk and Reliability Acceptance Criteria for Civil Engineering Structures. In.: Transaction of the VSB - Technical University of Ostrava, Civil Engineering Series 16 (2), p. 1-10.

EN 1993-1-1. Eurocode 3: Design of steel structures. Part 1-1 General rules and rules for buildings. ENV 1993-1-1, CEN 2003.

Haldar, A. Mahadevan, S. (2000) Probability, Reliability and Statistical Methods in Engineering Design. John Wiley \& Sons, New York.

IAEA Safety Standards, (2003) External Events Excluding Earthquakes in the Design of Nuclear Power Plants, No. NS-G-1.5, Vienna.

IAEA Safety Standards. (2011) Meteorological and Hydrological Hazards in Site Evaluation for Nuclear Installations. No. SSG-18, Vienna.

JCSS. (2001) Probabilistic Model Code, Joint Committee on Structural Safety, http://www.jcss.ethz.ch.

Kala, Z. (2011) Sensitivity analysis of steel plane frames with initial imperfections, Engineering Structures, 33, 8, pp.2342-2349, ISSN: 0141-0296, doi:10.1016/j.engstruct.2011.04.007.

Konečný, P. et al. (2009) Towards Parallel Computing using the Simulation-based Reliability Assessment Method. In. Proceedings of the First International Conference on Parallel, Distributed and Grid Computing for Engineering, Civil Comp Press, p. 542-549. ISBN 978-1-905088-29-4.

Králik, J. (2009) Safety and Reliability of Nuclear Power Buildings in Slovakia. Earthquake-Impact-Explosion. Edition STU Bratislava, $305 \mathrm{p}$.

Králik,J. (2015) Safety and Reliability of NPP in Slovakia Within IAEA Project "Stress Tests", pp.21-36 In: Monograph Selected Practical and Theoretical Aspects of Contemporary Mechanics, Ed. I. Major \& M. Major, Wydawnictwo Wydzialu Zarzadzania, Politechniki Częstochowskiej, Częstochowa, ISBN 978-83-65179-20-3.

Králik, J. (2017) Risk Assessment of NPP Safety in Case of Emergency Situations on Technology. In Recent Improvements of Power Plants Management and Technology. 1. vyd. Rijeka : InTech, S. 69-95. ISBN 978953-51-3357-5.

Králik, J. (2017) Actual Problems of the Safety and Reliability of the NPP Structures in Slovakia. In Static and Dynamic Analysis of Reinforced Concrete Structures. Trans Tech Publications, pp. 261-272. ISSN 1013-9826.

Krejsa, M. et al. (2016) Probabilistic Calculation Using Parallel Computing. In Engineering Mechanics 2016, pp. 347351. ISSN 1805-8248.

Melchers, R. E. (1999) Structural Reliability: Analysis and Prediction, John Wiley \& Sons, Chichester, U.K.

Novák, D. et al. (2003) Small-sample Probabilistic Assessment - software FReET, ICASP 9, 9th International Conference on Applications of Statistics and Probability in Civil Engineering, San Francisco, USA, July 6-9, pp. 91-96.

NRA SR. (2011) The stress tests for Nuclear Power Plants Slovakia, UJD Bratislava.

NRC, RG 1.200 (2009) An approach for determining the technical adequacy of probabilistic risk assessment results for risk-informed activities, U.S. NRC, Washington, DC. 2009.

SHMU. (2012) Summary report SHMÚ for locality Jaslovské Bohunice, SHMÚ Bratislava, january.

Sýkora, M. Holický, M. (2013) Assessment of Uncertainties in Mechanical Models, In: Applied Mechanics and Materials Vol. 378, pp 13-18, ( ) (2013) Trans Tech Publications, Switzerland. 